\title{
Preface on International Conference on Solidification Science and Processing
}

\author{
John Banhart ${ }^{1}$ - U. T. S. Pillai ${ }^{2}$ T. P. D. Rajan ${ }^{2}$ B. S. Murty ${ }^{3}$
}

Published online: 2 November 2018

(C) The Indian Institute of Metals - IIM 2018

We are pleased to bring out this special issue of Transactions of the Indian Institute of Metals (TIIM) containing extended version of select papers presented at the Seventh International Conference on Solidification Science and Processing (ICSSP7) held in Thiruvananthapuram during November 19-22, 2018. ICSSP, a triennial international conference, is being organized since 2001 to allow researchers to exchange their knowledge on recent advances in the broader field of solidification. In this series, the ICSSP7 is organized jointly by the National Institute of Interdisciplinary Science and Technology (CSIR-NIIST) and Indian the Institute of Technology Madras. The conference is chaired by Professor John Banhart, Technical University, Berlin, Germany and convened by Dr. U.T.S. Pillai, CSIR-NIIST.

The ICSSP7 has 71 invited oral presentations by eminent researchers in the field and 67 poster presentations by young researchers. This conference has invited oral and contributed poster presentations. The conference aims to bring together researchers from various countries working in different areas of solidification, to discuss the current state of knowledge and address challenges in this field.

The present special issue of TIIM consists of 41 selected papers from those presented at the conference. These manuscripts have been accepted for publication in TIIM after a thorough scrutiny by experts in the field. This special issue is also made available on-line from the TIIM website with the support of Springer. We hope that these papers find a good readership and receive attention.

The topics covered in this issue include fundamentals of solidification, solidification of alloys and composites, nonequilibrium solidification, in situ observations during solidification, advanced solidification processes, modelling and simulation of solidification processes and structures, advances in casting techniques, eutectic solidification, solidification of foams and syntactic composites. As you go through this issue, you will see articles on different aspects of solidification covering both fundamentals and applications.

We thank all the authors for contributing their latest work in this proceedings. Special thanks go to reviewers for their critical review, which has helped in maintaining high standards of the journal. We express our sincere gratitude to all the editorial staff of the TIIM and Springer for their immense support in bringing out this special issue possible within a very short period of time for distribution during the conference.

B. S. Murty

murty@iitm.ac.in

TU, Berlin, Germany

2 CSIR-NIIST, Thiruvananthapuram, India

3 IIT Madras, Chennai, India 